\title{
Smarticle Particles: Leveraging Emotional Intelligence for Organizational Performance within the Military
}

\author{
Justine Wopat, Charles Needham \\ Liberty University, Lynchburg, USA \\ Email: justine.wopat@hotmail.com,crneedham2@liberty.edu
}

How to cite this paper: Wopat, J., \& Needham, C. (2021). Smarticle Particles: Leveraging Emotional Intelligence for Organizational Performance within the Military. Open Journal of Business and Management, 9, 2605-2634.

https://doi.org/10.4236/ojbm.2021.95143

Received: August 9, 2021

Accepted: September 26, 2021

Published: September 29, 2021

Copyright $\odot 2021$ by author(s) and Scientific Research Publishing Inc. This work is licensed under the Creative Commons Attribution International License (CC BY 4.0).

http://creativecommons.org/licenses/by/4.0/

\begin{abstract}
The purpose of this research was to explore the failure of some leaders within the Air Force Technical Applications Center to leverage emotional intelligence, resulting in a decrease in organizational performance. The participants included members who work for the Air Force Technical Applications Center. A small sample, representative of the larger agency population, comprised unspecified numbers who underwent observation, and 21 of the 2302 total personnel participated in the interviews. Data collection consisted of observations, interviews with personnel, and organizational archival data. Data analysis included qualitative analysis and analysis for triangulation. Thematic analysis was used to analyze the data; 5 themes emerged: operational environment, the stigma associated with emotions and military members, resilience, transformation, and decision making. The study results indicated that when members of an organization do not understand a skill, such as emotional intelligence, they cannot wield it as effectively to enhance their decision-making and increase the organizational performance of their organization. The implementation for positive change includes the Air Force Technical Applications Center personnel can engage in a variety of potential implementation strategies to increase their emotional intelligence, thereby enhancing organizational performance and decision-making. Leaders considering strategies to implement for self-perception can look toward self-regard, selfactualization, and emotional self-awareness. Personnel who want to focus on self-expression can implement strategies to improve emotional expression, assertiveness, independence. Interpersonal managers can implement strategies on interpersonal relationships, empathy, and social responsibility.
\end{abstract}

\section{Keywords}

Emotional Intelligence, Leader, Performance 


\section{Background and Introduction}

Study subjects participate in their research in line with the parameters established in the foundation of the study (Shao et al., 2018). By creating this foundation, researchers introduce their line of inquiry, provide the context of the problem through the background information and problem statement, and give purpose to their efforts. Participants in the study remain focused by reviewing the research questions laid out in the foundation of the study. Researchers develop the nature of their research and research framework to scope the way ahead for their projects (Ranganathan, 2019). Readers can look to definitions of key terms and the assumptions, limitations, and delimitations when reviewing professional and academic literature to ensure they understand the concepts presented and the boundaries placed on the study. Researchers, in general, show the significance of their research to validate the level of effort to put forward in the research and provide a literature review to provide insight into the current body of knowledge that exists for their subject matter.

The foundation of the study sets the framework for the research into leadership, emotional intelligence, organizational performance, and decision-making at the Air Force Technical Applications Center within the Department of Defense. Readers will find the background of the problem, the problem and purpose statements, the research questions, and the nature of the study in the first section. Additionally, the subjects in the study will participate, providing information for the research framework, using terms specific for the research, as noted by the assumptions, limitations, and delimitations specified. Readers will find a discussion on the significance of the study and a review of the pertinent professional and academic literature. Finally, readers will find a discussion on the research method and design, reliability and validity, and the research findings.

Leaders who can develop or enhance their emotional intelligence will serve their followers better than if they simply choose to remain stagnant in their emotional intelligence development. Very limited research currently exists to capture the concepts or the potential that exists from having an emotionally intelligent leader in charge of military teams. More research needs to occur in this regard so that the military can realize opportunities that it has the potential to harness to gain a competitive advantage over those nations that have not considered linking such concepts. Emotionally intelligent leaders bring forth selfawareness, self-regulation, social skills, empathy, and motivation that can serve their teams well while also acting as a model for the behavior of future leaders.

Researchers began looking at Emotional Intelligence in the 1990s since they believed a linkage existed with the Intelligence Quotient (IQ) (Macht et al., 2019). An assumption exists that leaders within the Department of Defense did not train or prepare people to have and utilize emotional intelligence and that this adversely affects the organizational performance of its members. Braganza et al. (2018) highlighted the importance of emotional intelligence and resilience as an aspect of wellness that results in satisfied, more active personnel who have 
increased productivity within the workplace. The environment of the Department of Defense includes high-stress levels and a high operational tempo, so finding ways to mitigate these as risk factors that influence the performance of personnel proves of the utmost importance.

\subsection{Purpose Statement}

The purpose of this research was to explore the failure of some leaders within the Air Force Technical Applications Center to leverage emotional intelligence, resulting in a decrease in organizational performance. The target population included members who work for the Air Force Technical Applications Center. A small sample, representative of the larger agency population, comprised unspecified numbers who underwent observation, and 21 of the 2302 total personnel participated in the interviews.

\subsection{Research Question}

The following research questions guided this research in discovering the failure of leaders within the Air Force Technical Applications Center to use high levels of emotional intelligence resulting in the inability to optimize the organizational performance of their people.

RQ1: What role does the leader's emotional intelligence play in the leadership of his or her people?

RQ2: What is emotional intelligence for leaders within the Air Force Technical Applications Center?

RQ3: How do leaders within the Department of Defense leverage their emotional intelligence so they can effectively lead?

\subsection{Assumptions, Limitations, and Delimitations}

Researchers make assumptions when they take certain situations or knowledge for granted, without specifically proving the information accurate or false (Thompson, 2018). Three assumptions relate to this research. First, the research study participants accurately represented the people who serve at the Air Force Technical Applications Center (Schmalbach et al., 2020). To mitigate this risk, the participants fell within specific delimitations set forth for the study. Second, the research subjects responded truthfully (Greener, 2018). The subjects had the opportunity to reduce the risk of providing false information by receiving the opportunity to pass on participation in specific events if they did not feel comfortable or opting out of the study at any time. Finally, participants had knowledge about leadership, organizational performance, and decision-making (Gross \& Laamanen, 2018). Study subjects provided information about their level of experience regarding leadership, organizational performance, and decision-making to ensure this assumption did not increase the risk to the study's accuracy.

Researchers show limitations in their study to elucidate weaknesses in their research (Velte \& Stawinoga, 2017). The participants in the exploration into 
emotional intelligence contributed to the study, given four limitations. First, the research subjects participated in the study over a limited time. Second, the participants responded during a snapshot of time while working for the Air Force Technical Applications Center. Considering the limitation of time, any peer who reviews this study should keep in mind that this study does not serve as a generalization that could apply to the Air Force Technical Applications Center at any other time in history or the future.

Second, the research participants may not have paid sufficient attention to the tasks presented to them (Fischer et al., 2018). The subjects agreed to participate in this study while concurrently working at the Air Force Technical Applications Center, conducting their regular duties for the organization. Given the enormous workload and the need for prioritization, the participants may not have invested significant time in the study. The subjects mitigated this risk by responding to their requests for participation in various activities with a notification along with the requested response time. The participants also received reminders as the requested timelines approach if they had not responded with the requested information.

Third, researchers who have sample sizes smaller than the population they study need to find a way to gain confidence in their research process for those who participate in the project (Hennink et al., 2019). Researchers who utilize interviews in a case study can assuage concerns of small sample sizes by continuing to conduct interviews until reaching saturation (Lowe et al., 2018). Saturation occurs when contributions by the interviewees no longer provide added information for the study while also helping ensure researchers conduct studies that do not make findings on too little data (Thorne, 2020). For example, in this study into leveraging emotional intelligence to improve organizational performance and enhance decision-making, the sample size began with observations of the pool of 2302 personnel and with 15 interview participants and increased until saturation occurred, so the findings proved meaningful. When further observations and data analysis no longer provided new data, the request for additional interviews ceased.

Finally, the number of subjects who participated in the research study provided a limited look into the Air Force Technical Applications Center personnel. This process, therefore, did not serve as a generalization for all employees at the Air Force Technical Applications Center (Lin, 2018). However, since only a small fraction of the organization participated, their deliberate selection did span personnel with previous military experience, without prior military experience, with experience leading or following, with experience as a government civilian, and as a contractor working for the agency.

Researchers purposely set delimitations, or boundaries, to shape their study to control factors that can influence their investigation (Răzvan, 2019). For this study of the Air Force Technical Applications Center, the subjects fell within two delimitations. First, only Americans participated in this study into the associa- 
tion between a leader's use of emotional intelligence and organizational performance and decision-making (Gupta et al., 2019). By selecting only Americans, cultural influences from people living in different national environments did not influence the subjects' responses (Toglia et al., 2017). Peers reviewing this study should not expect the same results if they apply the findings to people from other nations.

Second, since various people work for the Air Force Technical Applications Center, the chosen subjects represented each category of human resources assigned to the agency. The subjects selected for this study represented the military, the government civil service, contracting, and upper-, mid-, and lower-level leadership of this organization. The participants impacted the study through variation since they represented diverse perspectives throughout the Air Force Technical Applications Center.

\subsection{Significance of the Study}

The participants in this research study into leadership, emotional intelligence, organizational performance, and decision-making helped fill gaps in the literature. Researchers need to continuously study various aspects of leadership since the actions of leaders have such a tremendous significance on the outcomes for their organizations (Xie, 2020). In addition, leaders are responsible for increasing organizational performance and making informed decisions for their workplaces (El Othman et al., 2020). Researchers have not filled all the gaps in the literature, so continuous research needs to occur to help increase the understanding of leadership as a practice.

People contribute to and determine the success of organizations (Grubb et al., 2018). By studying the behaviors and actions of leadership, researchers can contribute to the overall understanding of leadership and organizational behaviors (Xie, 2020). Followers rely upon their leaders to influence organizational performance and decision-making within their unit (El Othman et al., 2020). Continuous learning and discovery by researchers will facilitate the identification of gaps in the literature for specific topics and understanding the art of leadership and its impacts on organizations and people. Leaders and followers who participated in the study of leaders, emotional intelligence, organizational performance, and decision-making provided information that will add to the overall body of knowledge regarding these subjects while also showing biblical integration into these concepts.

\section{Literature Review}

Leaders practice five key positive behaviors when they lead their people (Díaz et al., 2019). When leaders incorporate positive leadership practices, their people will have a clear direction, more self-awareness, feel emboldened, and show cooperation (Hagan et al., 2018). Additionally, all people within society have their behaviors influenced by leaders, further emphasizing the importance of leaders 
adopting positive leadership practices to influence and guide their personnel within the workplace (Burnes et al., 2018). Followers can look to their supervisors to model the way, inspire a shared vision, challenge the process, enable others to act, and encourage the heart (Caza \& Posner, 2019).

Modelling the way in research. Majeed et al. (2017) researched to discover if the emotional intelligence modeled by leaders had a role in a person's transformational leadership abilities. Only 35 of the 255 academicians asked to participate in the research failed to respond to the survey they received asking about the correlation between transformational leadership, emotional intelligence, and organizational citizenship behaviors. The 220 participants involved in Majeed et al. (2017) study served as teachers in four separate public universities. The participants provided responses that reinforced the need for leaders to model emotional intelligence in their leadership practices. Majeed et al. (2017) highlighted that the study participants all came from Pakistan and may not prove out in other cultural contexts, suggesting the need for similar studies in different cultures. Majeed et al. (2017) stated that research into leadership topics leads to similar results between various nations.

Camuffo and Gerli (2018) researched if any correlation existed between leadership and management behaviors and the acceptance or adoption of lean initiatives to improve the organization by gaining efficiencies and effectiveness. Personnel in 26 companies from the geographic area of Northern Italy participated in the study. The participants worked at companies already embracing the concepts put forth in lean management and already engaged in planning for or executing the process of going lean. Nine of the 26 companies represented had come from multinational endeavors. The participants chosen served as lean officers or the top lean officer of the organization and subjected themselves to 1.5-hour interviews to discuss real events that had taken place during their service. The researchers then reviewed recordings of these interviews to identify specific lean management behaviors identified by the participants during the interview process. The participants discussed behaviors which the researchers correlated to those behaviors that represent transformational leadership as well. Camuffo and Gerli (2018) concluded that a leader's modeling behavior could relate to changes within an organization, increasing the likelihood of adopting lean initiatives.

\section{Theories}

Maslow's hierarchy of needs theory. Maslow created the hierarchy of needs theory to outline the needs all humans face, beginning with physiological needs (Brennan, 2016). Humans also need safety, love and belonging, ego and esteem, and finally, self-realization. People do not universally seek to work in leadership positions as a means of reaching their self-actualization level in Maslow's hierarchy of needs (Azad et al., 2017). Ștefan et al. (2020) highlighted the notion that leaders can positively influence the performance of their people by assuring 
that the employees' basic needs get fulfilled so that the employee can focus on higher-order needs of self-esteem and self-actualization.

McGregor's theory X and Y. Şahin et al. (2017) highlighted those transformational leaders that have a higher inclination towards McGregor's theory $\mathrm{Y}$ style, opting to empower their personnel instead of subscribing to theory $\mathrm{X}$ rather act in a very directive and untrusting ways toward their employees. Ravenelle (2019) noted that leaders who purposely avoid conflict behave in ways that mirror McGregor's theory X. McGregor used theory X to describe the phenomena of organizations that appear to have harmony but operate with underlying resentments indifference, and apathy (Şahin et al., 2017).

Rao (2016) noted that many managers opt for theory X behaviors even though this approach does not yield the best results for the individual or the organization. Employees whose leaders leverage McGregor's theory Y will feel committed to their work and find their goals lining up with those of the organization (Ravenelle, 2019). Managers who harness theory $Y$ help improve their workforce by helping them develop, and the organization improves as a result (Rao, 2016). McGregor used the theory Y construct to explain how managers can reduce the amount of supervision that needs to occur for the followers since they believe they can recognize and motivate their employees to want to do well (Ravenelle, 2019). When leaders understand the difference between behaving with McGregor's theory $\mathrm{X}$ and theory Y styles, they can deliberately leverage the better options to motivate their personnel and improve the organization (Hommelhoff, 2017).

Argyris and Schön's theories for action. Argyris and Schön created theories for action to demonstrate the correlation of a person's behavior and conduct with their thinking (Thorvaldsen \& Madsen, 2020). Researchers can study their theories in use by applying Argyris and Schön's theories for action in maintaining curiosity about their research participants (Raelin, 2019). Researchers who also recognize their preconceived notions and misperceptions can conduct less biased research since they understand the correlation of their behavior with their thought processes.

Leaders who avoid conflict without deliberately realizing it behave with theory-in-use actions (Thorvaldsen \& Madsen, 2020). Management can help people understand themselves and others better when educating them on linking their thoughts with their activities (Thorvaldsen \& Madsen, 2020). Thorvaldsen and Madsen (2020) described Argyris and Schön's theory of action, describing the linkage between people's thoughts and actions.

Transformational leadership theory. Samul (2020) noted that since 1980, the prevailing leadership theories had focused more predominantly on leadership with authentic, emotional, and ethical considerations. People subscribed mainly to the transformational leadership theory as the predominant theory since the 1980s (Hoch et al., 2018). Followers of transformational leaders will feel empowered by their leaders who delegate responsibilities to them and share 
their power (Zekan, 2017). Transformational leaders proactively seek to improve those that they lead. Transformational leaders do this by inspiring their followers by using such things as vision, increasing the connectedness between followers with the organization's mission, and showing all their followers that the followers can improve themselves and others. Zekan (2017) also noted that transformational leaders have followers who have great admiration, trust, and respect for their leaders who exhibit highly ethical behavior.

Servant leadership theory. Leaders who appear as "people persons" may utilize the behaviors shown in servant leadership (Gardner \& Holloway, 2019). Servant leaders focus their efforts on creating circumstances that benefit their people, even if that means they must sacrifice something for the good of their people (Xu \& Wang, 2020). Servant leaders put their people first and do what they can to serve and build up their followers. For this to have maximum effect, the servant leader must have high levels of emotional intelligence that can help them properly assess the situation they experience and understand the situation their followers' experience. Followers of servant leaders often experience high levels of loyalty to their leader since they know that the leader will use influence for good rather than for malicious activities (Gardner \& Holloway, 2019). When followers see the behaviors modeled by their servant leaders, they have a higher inclination to form close relationships with others within their organization (Xu \& Wang, 2020).

Contingency leadership theory. Under the contingency leadership theory, managers harness both objective and subjective measures and modify their behaviors to adjust their leadership style to match their contextual environment (Meng, 2016). Krishnakumar et al. (2019) discussed the contingency leadership theory, noting that leaders under this theory will recognize the situations they find themselves in and adjust their leadership styles and behaviors to maximize their efficiency and effectiveness. Sometimes, the leader utilizing contingency leadership will adapt their leadership style to accommodate their followers to maximize their effectiveness and efficiencies. Leaders who leverage contingency leadership alter their leadership practices to adjust to the situations around them to lead in the best ways possible for their organization (Horila \& Siitonen, 2020).

\section{Research Method and Design}

A researcher wanting to answer questions about a particular organization, like the Italian Air Force studied by Surace (2019), may choose to look at the single case study research methodology to set the framework to help them advance in their inquiry. Researchers utilize the single case study design when they seek to elucidate information about working environments or when they want to compare a few organizations to one another. The participants in this study came from the human resource pool of personnel working at the Air Force Technical Applications Center, which falls under the larger Department of Defense for the United States of America. The entire pool of 2302 personnel from the center had 
the potential for observation, and 21 participated in direct interview processes to provide insights into the use of emotional intelligence by people within their working environment to increase organizational performance. The Air Force Technical Applications Center study participants behaved in their typical operating environments, which allowed the researcher to capture their behaviors in field notes. In addition, they engaged through personal interviews directly that helped develop a better understanding of the impacts of emotional intelligence utilization across the organization.

\subsection{Discussion of Population}

The population of eligible participants included those members who work for the Air Force Technical Applications Center. Currently, 2302 personnel work for the Air Force Technical Applications Center (K. Johns, personal communication, 15 March 2020). This pool of personnel included military and civilian personnel, along with others in contract support roles. All the people in this workforce work towards accomplishing the mission and goals set forth by the current commander for the Air Force Technical Applications Center (K. Johns, personal communication, 22 August 2020). In this research participants formed a small sample, representative of the larger agency population, comprised of unspecified numbers who underwent observation and 21 of the 2302 total personnel who participated in the interviews.

\subsection{Discussion of Sampling}

Researchers rely upon sampling to choose a representative portion of people from a larger group since studies of an entire population to prove unwieldy (Turner, 2020). Campbell et al. (2020) discussed the importance of using the proper sampling method when conducting research. Examples of sampling methods include theoretical, purposive, and convenience (Campbell et al., 2020; Conlon et al., 2020; Hu \& Qin, 2018; McCrae \& Purssell, 2018). Researchers who seek to create a new theory culminating their research can harness the theoretical sampling method (Conlon et al., 2020). McCrae and Purssell (2018) compared the use of theoretical and purposive sampling methods. Researchers can employ the purposive sampling method to intentionally choose types of people for their study to make their research more meaningful (Campbell et al., 2020). Participants were selected because the researcher can easily access them from the convenience sampling method ( $\mathrm{Hu} \&$ Qin, 2018). I employed the purposive sampling method for this research. The participants purposely came from subpopulations within the organization to accurately represent the diverse workforce's viewpoints.

\subsection{Data Collection Plan}

\subsubsection{Data Collection}

For researchers conducting studies, carefully planning for data collection and 
analysis proves imperative to optimize the experience for those participating in the research and those conducting the study (Heath et al., 2018). Wheeldon (2018) noted that qualitative data collection primarily includes observations, interviews, and the review of documents and artifacts from the participants in the study. Korstjens and Moser (2018) highlighted that the preponderance of collection methods used for research includes observations, interviews, and focus groups. Overall, researchers need to plan for a data collection plan, instruments, and data organization for the data collection portion of their projects (Stieglitz et al., 2018).

Data Collection Plan

The data derived from observations, interviews with personnel, and organizational archival data contributed to this research. Siangchokyoo et al. (2020) highlighted the value that observations provide to the researcher for gaining insights into their specific area of study. Cox (2016) indicated that people can assess leadership traits through the interview process. Omer (2015) mentioned the impact that review and inclusion of archival can have on conducting research. The participants contributed information through observations, interviews, and archival, which helped gather the data necessary to conduct a comprehensive investigation into the organization.

The personnel selected for one-on-one interviews answered thirteen questions outlined in the interview guide. The interview lasted between 30 minutes and 2 hours.

The Interview Guide lays out specific interview questions used to guide participants to provide the specifically requested information. Interviewees answered interview questions $4,7,8$, and 12 to address RQ1. Respondents who provided information on questions $1,3,6,10$ addressed RQ2. Participants who provided information to questions 2, 5, 9, and 11 helped answer RQ3. Respondents who provided additional details for question 13 helped to answer RQ1, RQ2, or RQ 3, depending upon the information they provided and what insights it provided for the research project. The interviewees participated in interviews notionally planned for 30 minutes to one hour.

\subsubsection{Archival Data}

The personnel observed and interviewed provided indications of archival data that helped provide additional relevant information to fully discovering the extent to which personnel leverage emotional intelligence for improving organizational performance and decision making. Fusch et al. (2018) discussed the potential that archival data provides to the researcher for providing additional research insights. Velte and Stawinoga (2017) examined the value of leveraging archival information for increasing data collection when exploring an organization. During the data collection for this project, personnel mentioned archival data during interviews or observations, providing additional insight into the organization once reviewed and analyzed. 


\subsection{Data Organization and Analysis}

\subsubsection{Data Organization}

Participants provided data through observations, interviews, and archival. Davies and Fisher (2018) indicated the necessity for clearly coding data so that the researcher can appropriately organize the data to find recurring themes. Therefore, coding occurred with the letter $\mathrm{O}$, I, or A to indicate which data source the information came from; O for observations, I for interviews, and A for archival. Additionally, participants provided information as a leader, follower, or both; this data got binned as 1, 2, 3, respectively. Finally, the personnel provided information related to organizational performance and decision making; the coding $\mathrm{P}$ and $\mathrm{D}$ delineated this data from other sources.

A respondent who interviews and discusses their experience as a follower seeing decisions made within the organization could have their data coded as I2D as an example. On the other hand, personnel who show emotional intelligence in leadership and organizational performance could have their data annotated as O1P. A coding process proved vital when binning the data for analysis and determining what themes emerged from understanding the organization better (Hoch et al., 2018).

\subsubsection{Data Analysis}

Kim and Beehr (2018) mentioned how data analysis could help researchers extract meaningful themes and information during their studies. Han et al. (2017) noted the importance of data analysis for a researcher to use to help them identify themes to yield interpretations with high fidelity. Carillo et al. (2019) demonstrated how data proves invaluable for gaining understanding within organizations. Some considerations specific to data analysis for this study for strategic leadership included qualitative analysis and analysis for triangulation.

\subsection{Reliability and Validity}

Researchers can leverage data coding as a tool to help improve the reliability of research data (Seidel et al., 2019). Rose and Johnson (2020) proposed using standardized data collection methods across the study to increase the reliability of the collected information. The personnel evaluated for this research underwent observations, interviews, or review of archival data, as discussed previously. By establishing this data collection plan before research, the reliability of the study remained. Participant information received analysis based upon the data codes attributed to it. The data collection occurred as mentioned, with both coding and collection adding to the findings' reliability.

Rose and Johnson (2020) asserted that the validity of research could improve by having enough data to reflect the organization's reality. Engaging in interview saturation increased the validity of the data received since the more information overlaps, the more likely it represents the organization's reality. Sebele-Mpofu (2020) expressed that case study researchers could reach saturation when their interviews no longer yielded new or different, previously discovered informa- 
tion. Siangchokyoo et al. (2020) noted that the observations made of personnel can help to increase the validity of the research since it can reaffirm statements made by personnel during their interviews, thereby increasing the validity, or trustworthiness, of the information, gathered. Naidu and Prose (2018) stated that member validation serves to verify the credibility of the results received from the participants in a study. Caretta and Pérez (2019) detailed the importance of member checking as an avenue to a mutual understanding with the research subjects on the information they provided to come across accurately and as intended. The participants in this research had their information echoed back to them in the form of active listening. If the participant disagreed with the data captured, specific queries occurred as follow-on questions for clarification.

\section{Presentation of the Findings}

The field study participants who underwent observation and interviews provided information that informed qualitative analysis and led to the findings regarding leaders' use of emotional intelligence to enhance decision making and organizational performance. First, personnel gave insights that led to a discovery of themes within the realm of emotional intelligence. Second, people observed and interviewed provided information that received specific discussion compared to the research questions, the research framework, anticipated themes, and the literature review. Finally, the observed and interviewed personnel had their contributions evaluated to show a summary of the findings, including how the results addressed the specific problem studied, the general problem investigated, the purpose of the research, the research questions, and the conclusions drawn from the conclusions this study.

\subsection{Overview of Themes Discovered}

Personnel from the Air Force Technical Applications center provided information during the field study, which helped to illuminate themes regarding leadership and emotional intelligence once the data collected underwent qualitative analysis. The observed and interviewed members had their data assessed to flesh out the themes that arose from the study. When considering leaders and their use of emotional intelligence to increase organizational performance, five themes appeared. The participants provided information that led to discovering themes regarding the operational environment, the stigma associated with emotions and military members, resilience, transformation, and decision making.

\subsection{Discussion of Themes}

Operational environment. Members working for the Air Force Technical Applications Center encounter a dynamic operating environment to accomplish their mission. Leaders serving within the Department of Defense must prepare to conduct operations on the battlefield and in austere locations. The military organizations' personnel rely on their leaders to prepare them to work effectively 
in the various operational environments they can expect to encounter. People who know their duties include working in unfamiliar locations, and potentially hostile areas need leaders who can appreciate the emotional toll this may take on their personnel. Empathetic leaders who leverage their emotional intelligence understand the stressors brought on to their members from the dynamic operational environments they face.

Personnel observed during this field study served in a multitude of operational environments around the world. For example, the Air Force Technical Applications Center leaders had to lead and manage their team members working in laboratories, on airplanes, on deployed ships, and in operating locations geographically separated from the primary Air Force Applications Center headquarters building at Patrick Space Force Base in Florida. One member, Participant 9, highlighted the different operational environment he had encountered since entering the organization compared to when he was deployed in a combat environment serving alongside Air Force security forces personnel. Participant 9 commented, "I find myself trying to chameleon a lot," when asked to describe challenges he has had to face when leveraging emotional intelligence in this dynamic operational environment.

Resilience. Recognizing that servants in military organizations operate in unique operational environments and have emotions, leaders do best when they can bolster the resilience of their personnel. Personnel can increase their resilience by practicing mindfulness. Leaders who employ their emotional intelligence demonstrate to those around them ways to practice mindfulness and how to funnel that into organizational performance. Organizations put forth apparent efforts to enhance the resilience of their team members.

Observations of the Air Force Technical Applications Center personnel indicate that they do not have desired levels of resilience to optimize organizational performance. When personnel fail to acknowledge their emotional side, they have a more challenging time building up their resilience and impacting their decision-making and organizational performance. Observed leaders within the Air Force Technical Applications Center proved that they understood the need to improve the resilience of their personnel within the organization. Over five months, the organization held two mandatory center-wide events focused on educating their members on increasing their resilience and evaluating past encounters where they did or did not have the resilience necessary to perform at their highest ability. During his interview, Participant 1 stated, "Sometimes I am aware of how my emotions drive my actions. Sometimes I become too emotional, which can impact my performance when I take things too seriously."

Transformation. Personnel working within the Department of Defense and the Air Force Technical Applications Center have a keen awareness of transformation. Transformational leaders can positively affect the changes within an organization and increase organizational performance. Leaders who do not shy away from transformation can inspire their followers to embrace change as well. 
Followers who do not benefit from transformation within an organization other than change for change's sake have a more challenging time appreciating and accepting the changes their leadership demands them to make. For military organizations that want to succeed and remain agile, transformation must receive consideration at various times of an organization's existence.

Decision making. People who leverage their emotional intelligence make better and more informed decisions (El Othman et al., 2020). El Othman et al. (2020) researched that provided an additional triangulation source. El Othman et al. (2020) offered insights that served as a source of corroboration with the data from this field study. The participants who provided information through observations and interviews in this study resulted in a theme that supports the notion that persons who use their emotional intelligence as a tool to aid in their decisions make better decisions. Followers in organizations have higher confidence in their leaders, who use emotional intelligence when engaging in their decision-making process. By leveraging emotional intelligence in making decisions, leaders and managers gather more information to supply them with the most comprehensive sight picture necessary to make the most informed decisions.

For additional triangulation purposes, people who served within the Air Force Technical Applications Center at different periods of the organization's history provided insights from their experience. For example, participant 5, a retired Air Force officer, held positions at varying times over his career, which brought him to serve at the Air Force Applications Center as a military member, a contractor, and a government civil servant.

\subsection{Relationship of Findings to the Research Questions}

The participants in this research responded to interview questions aimed at uncovering whether leaders within the Air Force Technical Applications Center use high levels of emotional intelligence to optimize the organizational performance of their people. In response to the interviewees' actions and interest in the project, the interviews notionally planned for 30 minutes to 1 hour went anywhere from 35 minutes to 2 hours and 45 minutes when conducted for this field study. The interviewees' conversations remained focused on addressing each of the following research questions.

RQ1: What role does the leader's emotional intelligence play in the leadership of his or her people? Using RQ1 as a guide, research participants provided information to help assess their perceptions regarding the emotional intelligence of the Department of Defense leaders. In addition, interviewees who answered questions $4,7,8,12$, or 13 from the Interview Guide provided information to address RQ1.

Participant 15 described the importance of emotional intelligence in his leadership style while giving a specific example in his interview. When asked to relay a time he had to leverage emotional intelligence, Participant 15 stated, "Ha! I 
use it every day, seriously. Even when having a conversation with" a particular subordinate. "I have to understand where she's coming from, so she doesn't lock up." Observations of the subordinate mentioned above served as a source of triangulation, allowing for corroboration to leverage emotional intelligence as a tool to best lead this subordinate to increase her organizational performance within the organization.

RQ2: What is emotional intelligence for leaders within the Air Force Technical Applications Center? Like RQ1, RQ2 was used as a focal point to keep research participants on track to supply their perceptions regarding the emotional intelligence of the Department of Defense leaders. Respondents who provided answers to interview questions 1, 3, 6, 10, or 13 from the Interview Guide provided data that helped answer RQ2.

The observed and interviewed participants chosen for this field study included people on their first day with the organization to others who had extensive experience working for the Air Force Applications Center across various times in its history since its creation in 1947. Participant 10, a brand-new contractor at the center, participated in an interview on her second day while working for the organization. She stated, "When you're emotionally intelligent, you should be able to pick up on others' feelings. Unfortunately, not many people are good at picking up on others' emotions." Participant 5 served as a triangulation source since he had multiple times of service to the organization. In his interview, he equated emotional intelligence to stability. "Hopefully, being mature enough to deal with the positions they're put into without causing a lot of drama." Participant 5 also discussed why leaders need to have emotional intelligence:

People need emotional maturity to have conversations. Lieutenants here tend to send emails rather than talking to people. Communicating is a key thing we're telling people to do. They have academic competence, but they need help with social and emotional mentoring.

RQ3: How do leaders within the Department of Defense leverage their emotional intelligence so they can effectively lead? RQ3 served to keep personnel involved in this research on track to discover what the research participants thought regarding how leaders use emotional intelligence to facilitate their leadership and make it more effective within the Department of Defense. Participants who provided information in response to interview questions $2,5,9,11$, or 13 helped answer RQ3.

Recently, senior leaders within the Department of Defense have recognized the need to improve the emotional intelligence of its personnel to ensure better performance outcomes. Specifically, personnel responsible for authoring standardized forms and publications for the United States Air Force produced a new structure for leaders to give mandatory constructive feedback to their subordinates. As of 13 January 2021, supervisors in the Air Force can use the Airman Comprehensive Assessment Addendum, when evaluating their personnel. Spe- 
cifically, leaders need to distinguish how their people demonstrate their use of emotional intelligence in the workplace. Personnel have a requirement to exhibit self-awareness, understand emotions, and manage interpersonal relationships. Suppose an individual appears to have difficulty keeping themselves composed in the complex military environment. In that case, they will fall on the lower end of the scale since they do not meet the expectations of emotional intelligence. On the other hand, individuals who show outstanding levels of emotional intelligence use their skills to build teams and increase organizational performance. Until this year, none of the mandatory feedback forms within the Air Force included criteria for evaluating personnel and setting forth the expectation that people would leverage this skill in the workplace.

\subsection{Relationship of Findings to the Research Framework}

Jack et al. (2018) pointed out that researchers employ research frameworks to show the correlations between their studies and the process they used to conduct their research. The participants in the research study into emotional intelligence and organizational performance engaged in activities focused on the research framework. The research framework specifically created for this research included concepts, theories, actors, and constructs which served to help bring insights to the project to answer the three research questions outlined previously.

Concepts. Grubb et al. (2018) concluded that people who work for emotionally intelligent leaders would strive to perform better since they have confidence in their leaders' informed decisions. Furthermore, leaders and followers who leverage their emotional intelligence can increase their ability to make sound decisions and perform within the organization (Vaughan et al., 2019). This research into leveraging emotional intelligence to improve organizational performance and decision-making capabilities focused on the concepts of emotional intelligence, organizational performance, and decision making.

Emotional intelligence. Nguyen et al. (2019) discussed the imperative for leaders to communicate more effectively with their followers by using their emotional intelligence as a tool to lead more effectively. Of the 21 people interviewed for this study, six admitted to having no clue what emotional intelligence meant. On the other hand, seven of the 21 participants had mastery of the term emotional intelligence. The remaining eight of the 21 research subjects had relatively good guesses about the term emotional intelligence meant from contextual clues. Participant 4 currently serves as an officer in the Air Force with four years of active-duty service. During the interview process, Participant 4 relayed that she had some specific training on emotional intelligence. At the same time, she attended a Behavioral Science class in 2014 during her college experience at the United States Air Force Academy. Participant 4 relayed how she enjoyed the Behavioral Science class and how the topic of emotional intelligence has come up in small group discussions throughout her time in the Air Force, especially on down days used to focus on resiliency following suicides within the service. 
According to Participant 4, emotional intelligence appears with, "Someone empathetic, understanding, has good situational awareness, and can read the room while also placing themselves in another's shoes and see through their lens."

Organizational performance. Leaders have the responsibility for their organization's performance, and those who fail to leverage their emotional intelligence can negatively impact the overall performance of their organization through the toxic organizational climate full of anxiety and fear they create (Maamari \& Majdalani, 2017). All 21 respondents answered question seven from the Interview Guide, "How did/do you deal with emotional intelligence when thinking about increasing organizational performance and decision making?" Participant 20 answered, "I think it is an important factor because every decision has positive and negative outcomes. Therefore, you need to balance decisions to ensure organizational effectiveness." Following question seven, the participants answered question eight, "Tell me about a time when you had to leverage decision making within this organization." Participant 20 responded to question eight while describing an encounter with Participant 13, who served as his supervisor during the incident. Participant 20 replied:

My first flight commander had a different opinion with me, which we had discussed multiple times without success. Finally, one day, the situation came to a boiling point when we got a hot tasker, which led to a confrontation. We had to take a step back to see how we could move forward past that.

Leaders who want to enhance the organizational performance of their organization can start by leveraging their emotional intelligence to help them make better decisions. When leaders and their followers can monitor their emotions and respond appropriately to them, they can ensure that they keep the organization operating effectively.

Decision-making. For leaders to work successfully, they need to enhance their decision-making by utilizing their emotional intelligence to have the agility to react to stressors in the workplace (Farnia et al., 2018). Respondents in this study answered question 9, "What are the challenges you have had to face, or seen others face when leveraging, or not leveraging emotional intelligence to increase organizational performance and decision making?" Participant 21, the most informed on emotional intelligence, replied, "In my opinion, both organizational performance and decision making are impacted by low connections to emotional self-awareness, interpersonal relationships, and empathy, coupled with high connections to assertiveness, problem-solving, and independence." Leaders need to consider and manage all their resources when leading their organizations and making decisions to help their organization move forward to meet its goals.

Theories. Estape et al. (2018) indicated that leaders must strategically account for improving their workforce by taking care of their development if they want 
their organization to continually gain a competitive advantage over others. Those who follow a leader serve as another resource that the leader needs to manage when doing the best things to optimize their organization. The leaders of the Air Force Technical Applications Center had their use of emotional intelligence for organizational performance and decision making evaluated through the lenses of Maslow's hierarchy of needs theory, McGregor's theory X, and theory Y, Argyris and Schön's theories for action, transformational leadership theory, and contingency leadership theory (Li et al., 2019; Ravenelle, 2019; Siangchokyoo et al., 2020; Thorvaldsen \& Madsen, 2020).

Maslow's hierarchy of needs theory. Brennan (2016) described Maslow's hierarchy of needs theory by talking about its parts which show what humans feel motivates them to act. Humans feel inspired by their physiological needs, safety needs, love, belonging, esteem, and self-realization. Participants in this study responded to question 10, "In your current role, what do you think of emotional intelligence as part of your responsibilities?" Participant 9 serves as a first sergeant, nicknamed "The Shirt," within the Air Force Technical Applications Center. The person who acts as a first sergeant must know how to meet the needs of personnel since they often must help commanders navigate difficult situations with their personnel. Participant 9 responded to question 10, that:

Emotional intelligence is absolutely crucial. People come to the shirt, unfortunately, sometimes as a last resort. It is frustrating for us sometimes when we must help someone who has been dealing with issues on their own. I need to be careful and realize everything affects people differently. I have to approach people with sensitivity.

The first sergeant serves as an example of how leaders can manage their human resources in emotionally intelligent ways to ensure people have their Maslow's hierarchy of needs met to optimize their performance for the organization.

McGregor's theories X and Y. Management may respond to conflict within their workplace in ways reflective of McGregor's theory X and theory Y. Ravenelle (2019) noted that leaders who purposely avoid confrontation to keep everyone happy act according to the soft versions of McGregor's theory X. As noted previously with Participant 20 in his response to question eight, the interactions he had with his supervisor culminated in an unavoidable boiling point conflict since the supervisor had not dealt with their disagreement early on when it first came to bear. By acting per McGregor's theory X construct and avoiding conflict, the supervisor attempted to give the appearance of organizational harmony even though he had created a work environment characterized by indifference, apathy, and resentment. When leaders believe that their people commit to succeed and purposely line up their goals with those of the organization, they operate under McGregor's theory Y construct (Ravenelle, 2019). All research participants answered question four, "Do you think emotional intelligence is important to have as a leader and/or follower? Why, or why not?" Participant 4 responded: 
Definitely, at the end of the day, it's the people that get the mission done. You cannot get the people to buy in and go above and beyond without emotional intelligence. They will get the mission done, but it may not exceed expectations.

By leveraging emotional intelligence, leaders can improve organizational performance under the theory Y construct, which would help them minimize how much they must supervise their followers, giving them more time to focus on other areas within the organization.

Argyris and Schön's theory of action. Thorvaldsen and Madsen (2020) highlighted Argyris and Schön's theory of action, which discusses how a person's thoughts link to their actions. When managers behave in line with Argyris and Schön's theory of action, they subconsciously avoid conflict as a method of self-preservation. During the field study of this research, many situations yielded observations of various leaders throughout the organization for months. On multiple occasions, leaders demonstrated this theory by their behaviors when they subconsciously attempted to avoid conflict with their superior, who many viewed as a toxic leader. In another instance, Participant 5 discussed how he avoided conflict with his superior since he has not taken well to issues when trying to bring the conflict to the manager for resolution. Participant 5 also demonstrated his emotional intelligence during an inspection when his supervisor altered a planned presentation with inspectors without prior coordination, and Participant 5 remained calm, relaxed, and collected. Participant 5 discussed this issue with his manager's boss since the manager's unplanned actions left the member quite distraught. People within an organization who want to succeed need to face conflict to resolve issues and prevent adverse impacts on organizational performance.

Transformational leadership theory. Zekan (2017) indicated how transformational leaders yield followers who trust, admire, and respect their leader. In addition, transformational leaders exhibit high ethical standards, inspire their followers, and do not hesitate to delegate their authority or sharing their power with their followers. All study respondents answered question five, "Tell me about someone who is a role model for leveraging emotional intelligence to improve organizational performance and decision making within the organization." Participant 16 replied:

It's funny because I've had people tell me that I have it. I think the only person that has it is (Participant 21). He is the only person who called me when my mom died from COVID and showed me concern. Now I do trust him a lot more. I describe him as "normal."

Participant 21 inspired trust in Participant 16, which is not a surprise since Participant 21 proves to have expertise in emotional intelligence and currently works to spread knowledge of emotional intelligence throughout the organization to increase organizational performance. 
Contingency leadership theory. Krishnakumar et al. (2019) indicated that the contingency leadership theory indicates that leaders can increase their effectiveness if they can adjust their leadership style or behaviors in response to any given situation. Some of the personnel observed during the field study exemplified the contingency leadership theory. For example, participant 9 , the first sergeant, discussed how he changed his behaviors and leadership styles in the past to best respond to situations given to him by others. When discussing a time when he had to leverage emotional intelligence, he stated:

Times recently when I've had younger Airmen come in, having life troubles. I must forget what I've known about being an Airman because I'm older and have different values for my off time. Also, it's different being deployed in combat versus being here. Here I have to be more sensitive than I had to when deployed in combat with cops.

Leaders. The leaders present in this study include those who function as formal leaders and those who work as informal leaders within the Air Force Applications Center. Formal leaders serving at the Air Force Technical Applications Center include positional leadership roles and supervisory leadership roles. Only one participant selected for an interview considered themselves exclusively a formal leader. Positional leaders included those people in designated leadership roles where they have delegated authority and resources given to them on a large scale. Those individuals in supervisory leadership roles have a smaller scope of responsibility and fewer resources when compared to the formal leaders in positional leadership roles. Not all the interviewees from this field study identified themselves as leaders. One of the participants chosen for an interview explicitly stated that she did not view herself as a leader within the organization. Nevertheless, leaders throughout the organization had their behaviors observed, even if they did not participate in an interview.

Familiarity with emotional intelligence. Bakhshizadeh et al. (2019) research that emotional intelligence allows leaders to perceive emotional states within themselves and others. People from this study into emotional intelligence had to have their level of familiarity with emotional intelligence determined. The personnel assessed in this research had varying familiarity with emotional intelligence, from no familiarity to extensive and expert understanding of emotional intelligence. About emotional intelligence, at the beginning of his interview, Participant 12 declared, "This is the first I've heard of it. How you feel about certain things, how they affect you emotionally." At times, people can demonstrate emotional intelligence even if they do not believe they are familiar with the topic or skill. Participant 21, an accomplished doctoral graduate, identified by others as the organization's expert on emotional intelligence, self-reported an emotional intelligence rating of 7 on a scale of 1 to 10 , with 1 representing little to no emotional intelligence and 10 showing high emotional intelligence. In his interview, Participant 21 stated, "I find that because I work with emotional intelli- 
gence so much with other people, I am constantly reflecting on how I show up in the various composites each time I am preparing for a workshop or coaching session." Understanding the research subjects' familiarity with emotional intelligence helped determine if any correlations occurred with the use of emotional intelligence and decision making and organizational performance.

\subsection{Relationship of Findings to Anticipated Themes}

Operational environment. Department of Defense employees serve in unique settings which many others do not have to deal with when performing in their professions. Even though service members who work for the Department of Defense must prepare themselves to engage in battle with the nation's adversaries potentially, they cannot simply follow orders from the leaders above them and expect to survive. Since the Department of Defense does not rely solely upon robots to serve in combat, the leaders within the department must also know how to engage with their human warriors who have and show emotions. Observed personnel and the 21 interviewed participants in this study shared their personal experiences, which aided in the investigation to determine if evaluation and increase in the emotional intelligence of the personnel serving within the Department of Defense of the United States of America would have any value or efficacy when aimed to improve people's performance in these high-stress environments.

The stigma associated with emotions and military members. Garcia Zea et al. (2020) mentioned how Department of Defense service members often have the preconceived notion that they exist only as cold-hearted or heartless killers and warfighters. Most Americans do not have the unique responsibility of giving their own life or taking another life when performing their professional duties. Even though the Department of Defense members have requirements to engage in battle or support battle, they still have emotions and emotional capacity. When the Department of Defense members understand and know how to use their emotional intelligence, they will perform better in their highly stressful work environments and situations. As senior leaders understand more about the importance of soft leadership skills such as emotional intelligence in leadership, they have a greater inclination to invest in developing their personnel in these areas.

Resilience. Brock (2018) argued that members working for the Department of Defense required more emotional intelligence to enhance their resilience than those not working in such a demanding profession since the jobs within the department have high operational tempo, unique circumstances, and highly stressful environments. The numerous observed research subjects and the 21 interviewed participants in this study showed that leaders within the Department of Defense predominantly did not have the necessary levels of emotional intelligence which would have helped them to navigate the organization and make decisions more effectively, efficiently, and with more agility while increasing orga- 
nizational performance. At times, service members working within the Department of Defense must separate their emotions from the actions they need to accomplish so they do not have distractions to keep them from performing their duties. One senior leader within the Air Force Technical Applications Center repeatedly declared, "We are not emotional about this ... we are not going to have emotion. We are just going to fix the problem and move forward." People who collaborated directly with the senior leader and spent the most time with him understood the context of what he meant when he said not to act in emotionally responsive ways. Unfortunately, others within the organization did not interpret the senior leader's words in the same manner and declared him a toxic leader within the unit. For those who found the senior leader toxic, their resilience and ability to remain focused at work to exceed and maintain their contributions to the overall organizational performance appeared compromised.

Transformation. Xie (2020) discussed how transformational leaders impact their unit's organizational performance in positive ways. As expected, the 21 participants in this doctoral research study showed that the leaders who tended most to utilize their emotional intelligence effectively also served as transformational leaders, which, in turn, increased the organizational performance of their personnel. For the most part, those people who choose to operate inside the Department of Defense seek to make a difference in the world through their service to the nation and others. The service members who exhibit transformational leadership styles exhibit willingness to initiate, foster, and accept change to increase organizational performance.

Leaders play a large part in transforming organizations. In his interview, Participant 21 relayed the importance of emotional intelligence. Then, with a clear understanding of emotional intelligence, Participant 21 declared:

Simply stated, you can be the smartest person in the room, but if you can't get people to listen to you, it really doesn't matter how smart you are. One of the reasons emotional intelligences is so important to leaders is it addresses things not adequately unpacked in typical leadership training. Terms like, empathy, interpersonal relationships, self-awareness, reality testing, impulse control, flexibility, and optimism.

Several observed participants expressed concerns over leaders they felt did not transform the Air Force Technical Applications Center in ways that people could easily understand and support. Participant 5 mentioned how he had a tough time making a concerted effort not to stay one of those who remained bogged down by the old way of accomplishing the mission for the organization since he had worked there multiple times in a variety of positions during the center's existence.

Decision making. Another theme appears when people with high emotional intelligence make more informed decisions (El Othman et al., 2020). The 21 participants in this research study discussed how they believed emotionally intelli- 
gent leaders leveraged their emotional intelligence skills from within their leadership tool kits to facilitate making better, more informed decisions for themselves, their people, and their organizations. For example, participant 12, during his interview, commented, "When leaders make decisions, they need to think about their emotions." Those leaders who chose to engage their emotional intelligence as a tool to help in the decision-making process appeared as more competent leaders since they seemed to gather more information relevant to the situations they needed to navigate.

\section{Application of the Findings}

\section{Application to Professional Practice}

Bryan and Guccione (2018) researched to determine the career value; skills value, social value, and personal value that post-doctoral students found from attaining their degrees. In addition, personnel within organizations benefit when some of the people within their organization hold doctoral-level degrees. The following section outlines ways for improving general leadership practice and potential implementation strategies within organizations.

\section{Improving General Leadership Practice}

Kersemaekers et al. (2020) discussed the importance of improving leaders to ensure organizational success in high-stress environments. To enhance general leadership practice at the Air Force Technical Applications Center, personnel can learn more about emotional intelligence. People can expect to learn to improve their self-perception, self-expression, interpersonal, decision making, and stress management skills through the application of emotional intelligence. Emotionally intelligent individuals demonstrate self-perception through self-regard, self-actualization, and emotional self-awareness. When people engage in selfexpression, they can show emotional expression, assertiveness, and independence. Interpersonal leaders will show interpersonal relationships, empathy, and social responsibility. Effective decision-making personnel will employ problem solving, reality testing, and impulse control. To manage stress in their environment, leaders will practice flexibility, stress tolerance, and optimism.

\section{Recommendations for Further Study}

The following recommendations were considered for this research. First, researchers should investigate populations from high-stress and low-stress workplaces, teaching emotional intelligence to only half of each population and later studying the effects of the training on the employee's resilience. Second, researchers should seek to understand to what extent peer influence serves as a protective factor against Air Force military member suicides. Baker et al. (2021) discussed that suicides among military members actively serving in the United States Air Force almost doubled from 2001 to 2015. Finally, researchers ought to consider a longitudinal study of the training and implementation of emotional intelligence within the Department of Defense. Studying personnel from the six military 
branches over time who do and do not receive emotional intelligence training can help to highlight any differences that exist between the Air Force, Space Force, Army, Navy, Marines, and Coast Guard personnel.

\section{Limitations of the Research}

The participants in the exploration into emotional intelligence contributed to the study, given four limitations. First, the research subjects participated in the study over a limited time. The participants gave their responses during a snapshot of time while working for the Air Force Technical Applications Center. Due to the limitation of time, any peer who reviews this study should keep in mind that this study does not serve as a generalization that could apply to the Air Force Technical Applications Center at any other time in history or in the future.

Second, the research participants may not have paid sufficient attention to the tasks presented to them (Fischer et al., 2018). The subjects agreed to participate in this study while they concurrently work at the Air Force Technical Applications Center conducting their regular duties for the organization. Given the enormous workload and the need for prioritization, the participants may not have invested a large amount of time in the study.

In this study into leveraging emotional intelligence to improve organizational performance and to improve decision making, the sample size began with observations of the pool of 2302 personnel of the organization and with 15 interview participants and increased until saturation occurred, so the findings proved meaningful. When further observations and data analysis no longer provided new data, the request for additional interviews ceased.

Finally, the number of subjects who participated in the research study provided a limited look into the personnel at the Air Force Technical Applications Center and should, therefore, not serve as a generalization for all employees at the Air Force Technical Applications Center (Lin, 2018).

\section{Summary and Study Conclusion}

The observed and interviewed personnel contributed valuable information for the investigation into the Investigating Department of Defense leaders' general problem and the specific problem of leaders within the Air Force Technical Applications Center to fail to leverage emotional intelligence to increase organizational performance and decision making. The participants in this study provided insights that allowed for the conclusion that leaders within the Department of Defense and the Air Force Technical Applications Center fail to leverage emotional intelligence to increase organizational performance and decision making. While leaders did use emotional intelligence and others learned about emotional intelligence, the concept of emotional intelligence proved to be not widely understood nor standardized for maximum practical usage within organizations. As these organizations seek ways to improve national defense, they must incor- 
porate emotional intelligence as a force multiplier.

\section{Conflicts of Interest}

The authors declare no conflicts of interest regarding the publication of this paper.

\section{References}

Azad, N., Anderson, H. G., Brooks, A., Garza, O., O’Neil, C., Stutz, M. M., \& Sobotka, J. L. (2017). Leadership and Management Are One and the Same. American Journal of Pharmaceutical Education, 81, 102. https://doi.org/10.5688/ajpe816102

Baker, J. C., Bryan, C. J., Bryan, A. O., \& Button, C. J. (2021). The Airman's Edge Project: A Peer-Based, Injury Prevention Approach to Preventing Military Suicide. International Journal of Environmental Research and Public Health, 18, 3153. https://doi.org/10.3390/ijerph18063153

Bakhshizadeh, A., Talemi, A. N., Zadeh, G., Rahanejad, A. M., \& Shirvani, F. Z. (2019). Predicting of Borderline Personality Disorder (BPD) Based on Emotional Intelligence, Apathy and Empathy among the Soldiers Admitted to a Military Hospital. Revista Latinoamericana de Hipertension, 14, 74-82.

Braganza, S., Markwell, A., \& Jayasekara, S. (2018). Wellness, Resilience and Performance: Translating Ideas into Action. Emergency Medicine Australasia, 30, 263-265. https://doi.org/10.1111/1742-6723.12954

Brennan, C. (2016). Leadership and Management in Aesthetic Medicine. Plastic Surgical Nursing, 36, 19-23. https://doi.org/10.1097/PSN.0000000000000127

Brock, G. (2018). How Should We Combat Corruption? Lessons from Theory and Practice. Ethics \& International Affairs, 32, 103-117. https://doi.org/10.1017/S0892679417000508

Bryan, B., \& Guccione, K. (2018). Was It Worth It? A Qualitative Exploration into Graduate Perceptions of Doctoral Value. Higher Education Research and Development, 37, 1124-1140. https://doi.org/10.1080/07294360.2018.1479378

Burnes, B., Hughes, M., \& By, R. T. (2018). Reimagining Organisational Change Leadership. Leadership, 14, 141-158.

Campbell, S., Greenwood, M., Prior, S., Shearer, T., Walkem, K., Young, S., Bywaters, D., \& Walker, K. (2020). Purposive Sampling: Complex or Simple? Research Case Examples. Journal of Research in Nursing, 25, 652-661.

https://doi.org/10.1177/1744987120927206

Camuffo, A., \& Gerli, F. (2018). Modeling Management Behaviors in Lean Production Environments. International Journal of Operations and Production Management, 38, 403-423. https://doi.org/10.1108/IJOPM-12-2015-0760

Caretta, M. A., \& Pérez, M. A. (2019). When Participants Do Not Agree: Member Checking and Challenges to Epistemic Authority in Participatory Research. Field Methods, 31, 359-374. https://doi.org/10.1177/1525822X19866578

Carillo, K. D. A., Galy, N., Guthrie, C., \& Vanhems, A. (2019). How to Turn Managers into Data-Driven Decision Makers: Measuring Attitudes towards Business Analytics. Business Process Management Journal, 25, 553-578. https://doi.org/10.1108/BPMJ-11-2017-0331

Caza, A., \& Posner, B. Z. (2019). How and When Does Grit Influence Leaders' Behavior? Leadership and Organization Development Journal, 40, 124-134. 
https://doi.org/10.1108/LODJ-06-2018-0209

Conlon, C., Timonen, V., Elliott-O’Dare, C., O’Keeffe, S., \& Foley, G. (2020). Confused about Theoretical Sampling? Engaging Theoretical Sampling in Diverse Grounded Theory Studies. Qualitative Health Research, 30, 947-959. https://doi.org/10.1177/1049732319899139

Cox, J. A. (2016). Leadership and Management Roles: Challenges and Success Strategies. AORN Journal, 104, 154-160. https://doi.org/10.1016/j.aorn.2016.06.008

Davies, C., \& Fisher, M. (2018). Understanding Research Paradigms. JARNA: The Official Journal of the Australasian Rehabilitation Nurses' Association, 21, 21-25.

Díaz, E. R., Sánchez-Vélez, C., \& Santana-Serrano, L. (2019). Integrating the Five Practices of Exemplary Leadership Model into Entrepreneurship Education. International Journal for the Scholarship of Teaching and Learning, 13, Article e10. https://doi.org/10.20429/ijsotl.2019.130310

El Othman, R., El Othman, R., Hallit, R., Obeid, S., \& Hallit, S. (2020). Personality Traits, Emotional Intelligence and Decision-Making Styles in Lebanese Universities Medical Students. BMC Psychology, 8, Article No. 46.

https://doi.org/10.1186/s40359-020-00406-4

Estape, E. S., Quarshie, A., Segarra, B., San Martin, M., Ríos, R., Martínez, K., Ali, J., Nwagwu, U., Ofili, E., \& Pemu, P. (2018). Promoting Diversity in the Clinical and Translational Research Workforce. Journal of the National Medical Association, 110, 598-605. https://doi.org/10.1016/j.jnma.2018.03.010

Farnia, F., Nafukho, F. M., \& Petrides, K. V. (2018). Predicting Career Decision-Making Difficulties: The Role of Trait Emotional Intelligence, Positive and Negative Emotions. Frontiers in Psychology, 9, Article e01107. https://doi.org/10.3389/fpsyg.2018.01107

Fischer, A. H., Kret, M. E., \& Broekens, J. (2018). Gender Differences in Emotion Perception and Self-Reported Emotional Intelligence: A Test of the Emotion Sensitivity Hypothesis. PLOS ONE, 13, e0190712. https://doi.org/10.1371/journal.pone.0190712

Fusch, P., Fusch, G. E., \& Ness, L. R. (2018). Denzin's Paradigm Shift: Revisiting Triangulation in Qualitative Research. Journal of Social Change, 10, 19-32. https://doi.org/10.5590/JOSC.2018.10.1.02

Garcia Zea, D., Sankar, S., \& Isna, N. (2020). The Impact of Emotional Intelligence in the Military Workplace. Human Resource Development International, 1-17. https://doi.org/10.1080/13678868.2019.1708157

Gardner, P. K., \& Holloway, M. (2019). Organizations Need Ethical Leaders: How to Attract and Nurture Cultural Creatives into Positions of Leadership and Influence. Development and Learning in Organizations, 33, 8-11.

https://doi.org/10.1108/DLO-02-2019-0047

Greener, S. (2018). Research Limitations: The Need for Honesty and Common Sense. Interactive Learning Environments, 26, 567-568. https://doi.org/10.1080/10494820.2018.1486785

Gross, N., \& Laamanen, M. (2018). “The Knowledgeable Marketing Practitioner”: Practice and Professional Knowing in Marketing Work. Journal of Marketing Management, 34, 1172-1195. https://doi.org/10.1080/0267257X.2018.1542412

Grubb, A. R., Brown, S. J., \& Hall, P. (2018). The Emotionally Intelligent Officer? Exploring Decision-Making Style and Emotional Intelligence in Hostage and Crisis Negotiators and Non-Negotiator-Trained Police Officers. Journal of Police and Criminal Psychology, 33, 123-136. https://doi.org/10.1007/s11896-017-9240-2

Gupta, G., Salter, S. B., \& Lewis, P. A. (2019). Accounting Offshoring: The Role of Emo- 
tional Intelligence. Journal of Accounting and Management Information Systems, 18, 145-172. https://doi.org/10.24818/jamis.2019.02001

Hagan, O. C. K. K., Nsiah, P., Obiri-yeboah, D., Yirdong, F., Annan, I., Eliason, S., Nuvor, S. V., \& College, C. (2018). Vaccination against Hepatitis B in Ghana: A Pilot Study. Journal of Public Health in Africa, 9, 92-95. https://doi.org/10.4081/jphia.2018.721

Han, S. J., Chae, C., Macko, P., Park, W., \& Beyerlein, M. (2017). How Virtual Team Leaders Cope with Creativity Challenges. European Journal of Training and Development, 41, 261-276. https://doi.org/10.1108/EJTD-10-2016-0073

Heath, J., Williamson, H., Williams, L., \& Harcourt, D. (2018). It's Just More Personal: Using Multiple Methods of Qualitative Data Collection to Facilitate Participation in Research Focusing on Sensitive Subjects. Applied Nursing Research, 43, 30-35.

https://doi.org/10.1016/j.apnr.2018.06.015

Hennink, M. M., Kaiser, B. N., \& Weber, M. B. (2019). What Influences Saturation? Estimating Sample Sizes in Focus Group Research. Qualitative Health Research, 29, 1483-1496. https://doi.org/10.1177/1049732318821692

Hoch, J. E., Bommer, W. H., Dulebohn, J. H., \& Wu, D. (2018). Do Ethical, Authentic, and Servant Leadership Explain Variance above and beyond Transformational Leadership? A Meta-Analysis. Journal of Management, 44, 501-529.

https://doi.org/10.1177/0149206316665461

Hommelhoff, S. (2017). Implicit Managerial Theories about Followers and Customers. Journal of Service Theory and Practice, 27, 47-68. https://doi.org/10.1108/ISTP-05-2015-0124

Horila, T., \& Siitonen, M. (2020). A Time to Lead: Changes in Relational Team Leadership Processes over Time. Management Communication Quarterly, 10, 7-35.

Hu, Z., \& Qin, J. (2018). Generalizability of Causal Inference in Observational Studies under Retrospective Convenience Sampling. Statistics in Medicine, 37, 2874-2883. https://doi.org/10.1002/sim.7808

Jack, C. R., Bennett, D. A., Blennow, K., Carrillo, M. C., Dunn, B., Haeberlein, S. B., Holzman, D. M., Jagust, W., Jessen, F., Karlawish, J., Liu, E., Molinuevo, J. L., Montine, T, Phelps, C., Rankin, K. P., Rowe, C. C., Scheltens, P., Siemers, E., Snyder, H. M., Sperling, R., Elliott, C., Masliah, E., Ryan, R., \& Silverberg, N. (2018). NIA-AA Research Framework: Toward a Biological Definition of Alzheimer's Disease. Alzheimer's and Dementia, 14, 535-562. https://doi.org/10.1016/j.jalz.2018.02.018

Kersemaekers, W. M., Vreeling, K., Verweij, H., Van Der Drift, M., Cillessen, L., Van Dierendonck, D., \& Speckens, A. E. M. (2020). Effectiveness and Feasibility of a Mindful Leadership Course for Medical Specialists: A Pilot Study. BMC Medical Education, 20, Article No. 34. https://doi.org/10.1186/s12909-020-1948-5

Kim, M., \& Beehr, T. A. (2018). Can Empowering Leaders Affect Subordinates' Well-Being and Careers Because They Encourage Subordinates' Job Crafting Behaviors? Journal of Leadership and Organizational Studies, 25, 184-196. https://doi.org/10.1177/1548051817727702

Korstjens, I., \& Moser, A. (2018). Practical Guidance to Qualitative Research. Part 3: Sampling, Data Collection, and Analysis. European Journal of General Practice, 24, 9-18. https://doi.org/10.1080/13814788.2017.1375091

Krishnakumar, S., Perera, B., Persich, M. R., \& Robinson, M. D. (2019). Affective and Effective: Military Job Performance as a Function of Work-Related Emotional Intelligence. International Journal of Selection and Assessment, 27, 203-215.

https://doi.org/10.1111/ijsa.12239 
Li, Z., Chen, Z., \& Hui, Y. (2019). Portfolio Selection through Maslow's Need Hierarchy Theory. Applied Economics, 51, 364-372. https://doi.org/10.1080/00036846.2018.1496223

Lin, L. (2018). Bias Caused by Sampling Error in Meta-Analysis with Small Sample Sizes. PLoS ONE, 13, e0204056. https://doi.org/10.1371/journal.pone.0204056

Lowe, A., Norris, A. C., Farris, A. J., \& Babbage, D. R. (2018). Quantifying Thematic Saturation in Qualitative Data Analysis. Field Methods, 30, 191-207. https://doi.org/10.1177/1525822X17749386

Maamari, B. E., \& Majdalani, J. F. (2017). Emotional Intelligence, Leadership Style and Organizational Climate. International Journal of Organizational Analysis, 25, 327-345. https://doi.org/10.1108/IJOA-04-2016-1010

Macht, G. A., Nembhard, D. A., \& Leicht, R. M. (2019). Operationalizing Emotional Intelligence for Team Performance. International Journal of Industrial Ergonomics, 71, 57-63. https://doi.org/10.1016/j.ergon.2019.02.007

Majeed, N., Ramayah, T., Mustamil, N., Nazri, M., \& Jamshed, S. (2017). Transformational Leadership and Organizational Citizenship Behavior: Modeling Emotional Intelligence as Mediator. Management and Marketing, 12, 571-590.

https://doi.org/10.1515/mmcks-2017-0034

McCrae, N., \& Purssell, E. (2018). Response to "Calling for a Shared Understanding of Sampling Terminology in Qualitative Research: Proposed Clarifications Derived From Critical Analysis of a Methods Overview by McCrae and Purssell” by Stephen Gentles and Silvia Vilches (International Journal of Qualitative Research, 2017). International Journal of Qualitative Methods, 17, 1-2. https://doi.org/10.1177/1609406918804684

Meng, Y. (2016). Spiritual Leadership at the Workplace: Perspectives and Theories. Biomedical Reports, 5, 408-412. https://doi.org/10.3892/br.2016.748

Naidu, T., \& Prose, N. (2018). Re-Envisioning Member Checking and Communicating Results as Accountability Practice in Qualitative Research: A South African Community-Based Organization Example. Forum: Qualitative Social Research, 19, Article 26.

Nguyen, T., White, S., Hall, K., Bell, R. L., \& Ballentine, W. (2019). Emotional Intelligence and Managerial Communication. American Journal of Management, 19, 54-64. https://doi.org/10.33423/ajm.v19i2.2068

Omer, A. (2015). Nationalism and the Comparative Study of Religious Ethics: Future Trajectories. Soundings: An Interdisciplinary Journal, 98, 322-353. https://doi.org/10.5325/soundings.98.3.0322

Raelin, J. A. (2019). Toward a Methodology for Studying Leadership-as-Practice. Leadership, 16, 480-508. https://doi.org/10.1177/1742715019882831

Ranganathan, P. (2019). Understanding Research Study Designs. Indian Journal of Critical Care Medicine, 23, S305-S307. https://doi.org/10.5005/jp-journals-10071-23314

Rao, M. B. (2016). Motivation of Teachers in Higher Education. Journal of Applied Research in Higher Education, 8, 469-488. https://doi.org/10.1108/JARHE-08-2015-0066

Ravenelle, A. J. (2019). “We're Not Uber:” Control, Autonomy, and Entrepreneurship in the Gig Economy. Journal of Managerial Psychology, 34, 269-285.

https://doi.org/10.1108/JMP-06-2018-0256

Răzvan, A. (2019). Implications of CJEU Jurisprudence on the Delimitation of Working Time by Rest Time in the Collaborative Economy. Lex et Scientia International Journal, 26, 7-25.

Rose, J., \& Johnson, C. W. (2020). Contextualizing Reliability and Validity in Qualitative 
Research: Toward More Rigorous and Trustworthy Qualitative Social Science in Leisure Research. Journal of Leisure Research, 51, 432-451.

https://doi.org/10.1080/00222216.2020.1722042

Şahin, F., Gürbüz, S., \& Şeşen, H. (2017). Leaders' Managerial Assumptions and Transformational Leadership: The Moderating Role of Gender. Leadership \& Organization Development Journal, 38, 105-125. https://doi.org/10.1108/LODJ-11-2015-0239

Samul, J. (2020). Spiritual Leadership: Meaning in the Sustainable Workplace. Sustainability, 12, 267. https://doi.org/10.3390/su12010267

Schmalbach, B., Roenneberg, C., Hausteiner-Wiehle, C., Henningsen, P., Brähler, E., Zenger, M., \& Häuser, W. (2020). Validation of the German Version of the Bodily Distress Syndrome 25 Checklist in a Representative German Population Sample. Journal of Psychosomatic Research, 132, Article ID: 109991. https://doi.org/10.1016/j.jpsychores.2020.109991

Sebele-Mpofu, F. Y. (2020). Saturation Controversy in Qualitative Research: Complexities and Underlying Assumptions. A Literature Review. Cogent Social Sciences, 6, Article ID: 1838706. https://doi.org/10.1080/23311886.2020.1838706

Seidel, A., Saurin, T. A., Tortorella, G. L., \& Marodin, G. A. (2019). How Can General Leadership Theories Help to Expand the Knowledge of Lean Leadership? Production Planning and Control, 30, 1322-1336. https://doi.org/10.1080/09537287.2019.1612112

Shao, Z. Y., Li, Y. M., Hui, F., Zheng, Y., \& Guo, Y. J. (2018). Interdisciplinarity Research Based on NSFC-Sponsored Projects: A Case Study of Mathematics in Chinese Universities. PLoS ONE, 13, e0201577. https://doi.org/10.1371/journal.pone.0201577

Siangchokyoo, N., Klinger, R. L., \& Campion, E. D. (2020). Follower Transformation as the Linchpin of Transformational Leadership Theory: A Systematic Review and Future Research Agenda. Leadership Quarterly, 31, Article ID: 101341. https://doi.org/10.1016/j.leaqua.2019.101341

Ștefan, S. C., Popa, S. C., \& Albu, C. F. (2020). Implications of Maslow's Hierarchy of Needs Theory on Healthcare Employees' Performance. Transylvanian Review of Administrative Sciences, 16, 124-143. https://doi.org/10.24193/tras.59E.7

Stieglitz, S., Mirbabaie, M., Ross, B., \& Neuberger, C. (2018). Social Media Analytics-Challenges in Topic Discovery, Data Collection, and Data Preparation. International Journal of Information Management, 39, 156-168.

https://doi.org/10.1016/j.ijinfomgt.2017.12.002

Thompson, S. (2018). Letters: Challenging Research Assumptions from an Indigenous Perspective. CMAJ, 190, Article e1233. https://doi.org/10.1503/cmaj.70181

Thorne, S. (2020). The Great Saturation Debate: What the “S Word” Means and Doesn't Mean in Qualitative Research Reporting. Canadian Journal of Nursing Research, 52, 3-5. https://doi.org/10.1177/0844562119898554

Thorvaldsen, S., \& Madsen, S. S. (2020). Perspectives on the Tensions in Teaching with Technology in Norwegian Teacher Education Analysed Using Argyris and Schön's Theory of Action. Education and Information Technologies, 25, 5281-5299. https://doi.org/10.1007/s10639-020-10221-4

Toglia, J., Lahav, O., Ben Ari, E., \& Kizony, R. (2017). Adult Age and Cultural Differences in Performance on the Weekly Calendar Planning Activity (WCPA). The American Journal of Occupational Therapy, 71, 1-8. https://doi.org/10.5014/ajot.2016.020073

Turner, D. P. (2020). Sampling Methods in Research Design. Headache, 60, 8-12. https://doi.org/10.1111/head.13707

Vaughan, R., Laborde, S., \& McConville, C. (2019). The Effect of Athletic Expertise and 
Trait Emotional Intelligence on Decision-Making. European Journal of Sport Science, 19, 225-233. https://doi.org/10.1080/17461391.2018.1510037

Velte, P., \& Stawinoga, M. (2017). Integrated Reporting: The Current State of Empirical Research, Limitations and Future Research Implications. Journal of Management Control, 28, 275-320. https://doi.org/10.1007/s00187-016-0235-4

Wheeldon, J. (2018). Reflection/Commentary on a Past Article: Framing Experience: Concept Maps, Mind Maps, and Data Collection in Qualitative Research. International Journal of Qualitative Methods, 17, 1-2. https://doi.org/10.1177/1609406918790673

Xie, L. (2020). The Impact of Servant Leadership and Transformational Leadership on Learning Organization: A Comparative Analysis. Leadership and Organization Development Journal, 41, 220-236. https://doi.org/10.1108/LODJ-04-2019-0148

Xu, A. J., \& Wang, L. (2020). How and When Servant Leaders Enable Collective Thriving: The Role of Team-Member Exchange and Political Climate. British Journal of Management, 31, 274-288. https://doi.org/10.1111/1467-8551.12358

Zekan, S. B. (2017). Organizational Culture and Leadership Style Key Factors in the Organizational Adaptation Process. Ekonomski Vjesnik, 30, 209-219. 